\title{
LAS FINANZAS PÚBLICAS DE LA CONFEDERACIÓN GRANADINA Y LOS ESTADOS UNIDOS DE COLOMBIA 1850-1886
}

\author{
Salomón Kalmanovitz* \\ Edwin López R.**
}

$\mathrm{E}$

n ese trabajo se comparan los ingresos fiscales del gobierno central la descentralización política y de rentas favoreció la sostenibilidad de las finanzas colombianas en este período crucial de la historia del país. Se contrasta la estructura federalista con la organización centralista que precedió y sucedió este periodo y se intenta evaluar cuál fue más favorable para la consecución de equilibrios macroeconómicos, en los ámbitos central y descentralizado. Aquí, sostenibilidad denota solvencia o capacidad de los Estados y del gobierno central para mantener sus balances en relativo equilibrio durante el periodo.

Usamos fuentes primarias como los informes de los secretarios del tesoro y los presidentes de algunos Estados federales, y los anuarios estadísticos de 1875 y 1876. Y nos apoyamos en las investigaciones de Deas (1980), Melo (2008) y Clavijo (1993) para el Tolima, entre otros.

La estructura tributaria es una de las principales instituciones alrededor de las cuales se organizan las sociedades: determina la asignación de parte de los recursos de la sociedad con fines de bienestar

\footnotetext{
* Magíster en Economía, Decano de la Facultad de Ciencias Económico-Administrativas de la Universidad Jorge Tadeo Lozano, Bogotá, Colombia, [salomon. kalmanovitz@utadeo.edu.co].

** Magíster en Ciencias Económicas, investigador y docente de la Facultad de Ciencias Económico-Administrativas de la Universidad Jorge Tadeo Lozano, Bogotá, Colombia, [edwin.lopez@utadeo.edu.co]. Agradecemos a Juan E. Vélez de la Universidad de Antioquia y Carlos A. Salazar de la UJTL quienes nos facilitaron datos preliminares de sus investigaciones sobre finanzas públicas de los Estados de Antioquia y Cauca. Así como a Liliana Guatava y Diego López de la UJTL, quienes están haciendo sus tesis de grado sobre las finanzas de Boyacá y Santander. Cualquier error y omisión son responsabilidad nuestra. Fecha de recepción: 12 de septiembre de 2010, fecha de modificación: 5 de octubre de 2010, fecha de aceptación: 21 de octubre de 2010.
} 
colectivo y de progreso económico. Las sociedades liberales crearon Estados fuertes, financiados con altos niveles de tributación local y nacional que contribuyeron a su crecimiento económico e incluso a que se convirtieran en imperios políticos. El problema de la tributación incluye la determinación del recaudo fiscal suficiente para construir la infraestructura y el capital humano que faciliten y aceleren el desarrollo económico. La eficiencia y la justicia de los tributos tienen importantes antecedentes teóricos en los fundadores de la economía política, que establecieron la conveniencia de su universalidad y su progresividad, y consideraron el federalismo como un sistema adecuado y legítimo de organización económica eficiente y competitiva, como se observa en los trabajos clásicos de Bentham, Smith y Mill. También se encuentran referentes teóricos en corrientes recientes cuyas teorías y modelos analizan el impacto de la competencia política y de las instituciones en el desempeño económico de los países y sus regiones, bien sea acudiendo a la teoría de la elección social, a la economía pública o a la interacción estratégica formalizada mediante la teoría de juegos.

La producción bibliográfica sobre el periodo federal en Colombia usualmente sigue tres orientaciones: en primer lugar, las reformas económicas de los gobiernos radicales produjeron anarquía y atraso económico, conforme al revisionismo de Indalecio Liévano Aguirre, que reivindica a Rafael Núñez; la segunda es intermedia, en el sentido de sostener que las reformas provocaron desigualdad y reducción del nivel de vida de los colombianos en el corto plazo, pero sentaron las bases de la modernización y la industrialización de principios del siglo XX (McGreevey, 1975, y Urrutia, 1969); la tercera señala el impacto favorable de dichas reformas en la revitalización de la política municipal, en el mejor desempeño del sector exportador y en los efectos sobre los demás sectores de la economía (Ocampo, 1984, y Jaramillo y Meisel, 2010). El debate no solo se concentra en los aspectos fiscales, sino en las distintas reformas económicas y políticas del Periodo Radical, muchas de ellas anteriores a la Constitución de Rionegro, como la desamortización de bienes de manos muertas, la creación de un sistema de banca libre que remplazó al monopolio eclesiástico del crédito, la división política, la abolición de la esclavitud, la descentralización de rentas, la liquidación de los monopolios fiscales, la libertad de culto y de prensa, y la abolición del fuero eclesiástico.

Una de las organizaciones políticas que más controversia ha generado en la historia colombiana es la del federalismo fiscal ${ }^{1}$. Sin embar-

1 Otra reforma liberal que ha desatado polémica en la historiografía es la 
go, no son abundantes los trabajos que lo analizan. Hace treinta años, Malcolm Deas señaló que las investigaciones sobre el problema fiscal del siglo XIX eran escasas, a pesar del gran debate sobre las políticas económicas de mediados del siglo XIX, tendencia que se extendía al resto de América Latina (Deas, 1980).

En los últimos treinta años se han publicado trabajos que tienden a explorar fuentes primarias y a cuantificar las rentas y los gastos, del gobierno central y de cada Estado soberano, lo que permite precisar los alcances del federalismo. La literatura reciente reconoce que en la década de 1850 se abandonaron definitivamente muchas de las instituciones fiscales que se mantenían desde la Colonia, en particular los estancos y la captura de rentas por el gobierno; cuantifica los principales recaudos, y muestra que las rentas del antiguo orden colonial languidecieron durante el periodo republicano (Jaramillo et al., 1999). Con base en las memorias de hacienda y del tesoro del gobierno nacional se han construido series de ingresos, de gastos y de partidas específicas para el gobierno central, y alguna información sobre los gobiernos locales que muestra el fuerte crecimiento de las rentas estatales entre 1851 y 1870 (Junguito, 2010); resultados que corroboran los de Malcolm Deas de 1980 y de José A. Ocampo (1984), quien señaló el éxito de los Estados soberanos para aumentar las rentas fiscales. En un estudio anterior (Kalmanovitz, 2006) se analizó el periodo de los Estados Unidos de Colombia a la luz de los estudios de Barry Weingast (1995), quien estableció algunos principios teóricos que debía cumplir todo régimen federal favorable al desarrollo de largo plazo. Ese estudio identificó algunas de las causas de la crisis de sistema federal en Colombia que se desató en la década de 1870: la falta de escenarios de negociación adecuados, la debilidad del Estado central para actuar como árbitro y monopolizar y limitar el uso de la violencia, la politización de la justicia, los abusos en el ejercicio electoral y la dificultad de los gobiernos, local y descentralizados, para someterse a restricciones presupuestales.

Las investigaciones sobre las finanzas regionales del siglo XIX suelen enfrentar una escasez de información cuantitativa y cualitativa, que se encuentra dispersa en diferentes archivos. Pero existen algunas investigaciones que abordan la problemática regional de manera

desamortización de bienes de manos muertas. En contra de la descalificación de sus efectos en las obras de Luis E. Nieto Arteta, Luis O. Vásquez y Álvaro Tirado Mejía, hoy se concluye que fue una de las reformas económicas más importantes del siglo XIX, que arrebató a la iglesia bienes y préstamos por un valor cercano a 20 millones de pesos de la época, un 16\% del PIB de 1860 (Jaramillo y Meisel, 2010). 
cuantitativa, por ejemplo, sobre el Tolima, Estado que se separó de Cundinamarca con la Constitución de 1863, y en el cual se observa una relación entre aspectos bélicos y monopolio fiscal en la segunda mitad del siglo XIX (Clavijo, 1993). En el caso de Bolívar y las provincias del norte del país, cabe resaltar el esfuerzo de recopilación de los informes de los presidentes y gobernadores del Estado y de las provincias, que no sólo contienen valiosa información fiscal, sino del desarrollo político y social de la región a mediados del siglo XIX (Solano, 2007). En el caso de Santander, se ha estudiado la administración de la renta del aguardiente (Páez, 1998). También existe un estudio general de distintos aspectos del Estado Soberano del Cauca entre 1858-1885 (Ortiz, 1986).

Este ensayo consta de tres secciones. En la primera se analizan los ingresos del Estado central y en la segunda, los ingresos fiscales de cada Estado. En la segunda sección se hace un breve examen de los gastos de los Estados y del gobierno central, y en la tercera se presentan las conclusiones.

\section{COMPORTAMIENTO FISCAL DEL ESTADO CENTRAL}

A comienzos del siglo XIX, e inmediatamente después de que el actual territorio colombiano se independizara del dominio español, afloraron proyectos para constituir el nuevo orden político que remplazaría a la estructura colonial, lo que generó intensos conflictos sobre la conveniencia de un control centralista o un reparto regional del poder político en la naciente república. Estas dos posiciones ideológicas llevaron a la formación de bandos armados que se enfrentarían en varias guerras civiles, como las del periodo que en la historiografía tradicional se conoce como "Patria Boba", y que se repitieron en la cruenta historia del siglo XIX. Lo que estaba en juego era la concesión de poder en los ámbitos económico, político y judicial a las regiones que se habían delimitado en la escarpada geografía del país y que se declararon Estados soberanos, contra un fuerte poder central ejercido por facciones e intereses que aspiraban a imponer su hegemonía y sus proyectos políticos a las regiones.

Luego del Congreso de Cúcuta en 1821 se estableció la Gran Colombia, máxima expresión de la unión del norte del subcontinente, con características de nación confederada integrada por los actuales territorios de Colombia, Venezuela, Ecuador y parte del norte de Brasil. La dictadura bolivariana (1828-1830) dio facultades similares a las que ella misma disfrutaba a los jefes regionales de Venezuela y 
Ecuador, y prefiguró la separación que ocurriría en 1832 al destruir las condiciones de libre deliberación que habrían permitido una confederación (Bushnell, 295). Después de la disolución de la Gran Colombia a comienzos de la década de 1830, el antiguo Estado de Cundinamarca se reorganizó en un Estado centralista con el nombre de República de la Nueva Granada.

En los poco más de sesenta años que transcurrieron entre la junta de gobierno de 1810 y la Constitución de Rionegro, las finanzas públicas de la nueva república fueron afectadas por las guerras de Independencia y los requerimientos de la reorganización política y administrativa del sistema político que remplazaría al colonial. Las crecientes necesidades fiscales era cubiertas con deuda y con los ingresos de algunas instituciones heredadas del régimen español, como las rentas estancadas y algunos impuestos al comercio exterior, en contra de las doctrinas liberales que inspiraban el pensamiento económico de muchos dirigentes de la época. Los pocos datos disponibles confirman los continuos déficit del tesoro público a nivel central en 1842 y $1851-1854$, pero principalmente entre 1880 y 1900 (Junguito, 2010), lo que evidencia la precariedad de las fuentes de financiación del gobierno. E1 recurso a préstamos forzosos durante las guerras y a préstamos garantizados con títulos sobre tierras baldías no fomentó la formación de un mercado local de capitales que financiara mayores faltantes, mientras que la moratoria de la deuda con Inglaterra cerró las puertas del crédito internacional hasta la segunda década del siglo XX. Los déficit aumentaron ya en los años setenta, al surgir un sistema de banca libre que tuvo que prestar a los gobiernos para mantener sus permisos de funcionamiento. La creación del Banco Nacional y su posterior monopolio de la emisión monetaria permitió la financiación inflacionaria y endémica de los faltantes fiscales del gobierno central, y también generó volatilidad en la tasa de cambio.

Aunque las rentas del gobierno nacional aumentaron pari passu con las exportaciones, no hubo un avance sustancial con respecto al PIB ni al PIB per cápita. Al menos entre 1870 y 1890, el gasto del gobierno central fue de un 5\% del PIB, lo que indica un progreso en su consolidación, pues el Estado como tal prácticamente se disolvió después de la Independencia y fue afectado por la inestabilidad política después de la disolución de la Gran Colombia, que derrumbó la idea bolivariana de unir a los Estados latinoamericanos, y obligó a los tres nuevos Estados a reiniciar su organización burocrática y política. 
Gráfica 1

Déficit fiscal del gobierno central

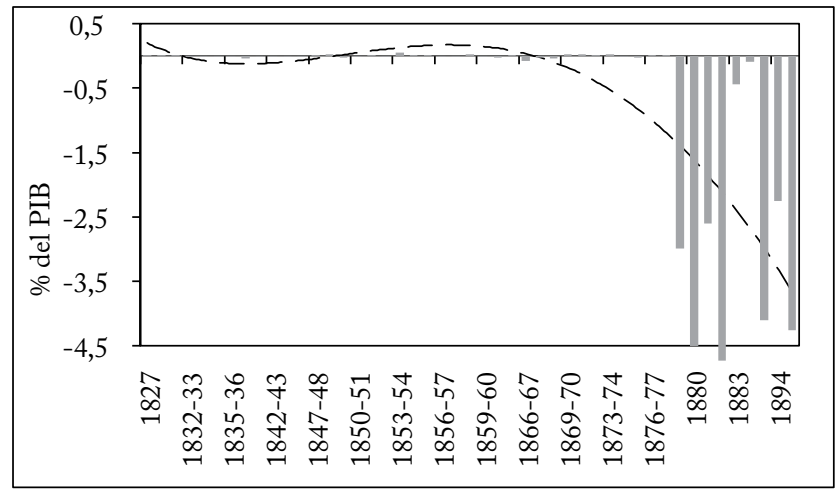

Fuente: Junguito (2010), Kalmanovitz y López (2009); cálculos propios.

Gráfica 2

Impuestos del gobierno, 1771-1990

(Porcentaje del PIB)

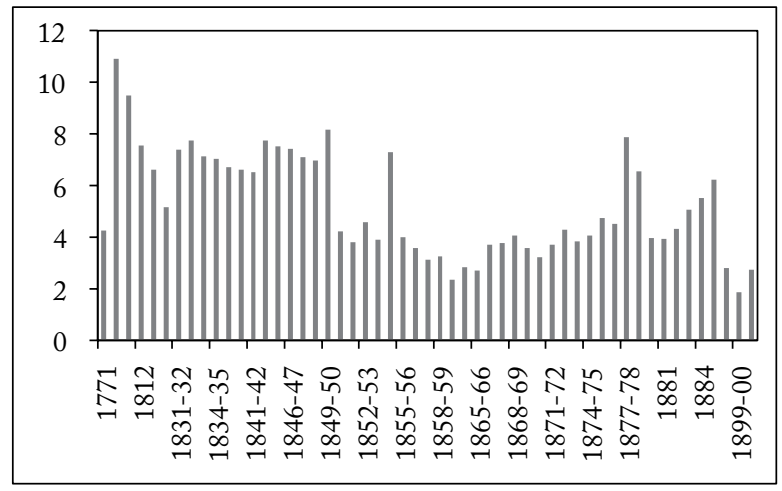

Fuente: Kalmanovitz y López (2009).

Durante el siglo XIX las principales rentas del erario nacional fueron los impuestos al comercio exterior, como muestra la gráfica 3. Con el auge de las exportaciones desde mediados de siglo, la participación del recaudo de aduanas en el total pasó de un $25 \%$ a un $60 \%$ en 1880 , y después se mantuvo relativamente estable, con una tendencia creciente hacia finales del siglo. Buena parte de los impuestos recaían sobre las importaciones de textiles, lo que producía una gran desigualdad en el reparto de la carga porque eran de consumo popular, y además consistían en impuestos específicos por unidad, de modo que una yarda de tela burda de algodón pagaba la misma tarifa que una de 
seda japonesa, sobre ingresos muy disímiles, lo que penalizaba el consumo de los trabajadores (Ocampo y Montenegro, 1984). Debido al cambio técnico en la industria británica y a la revolución en el transporte a larga distancia, los precios de los textiles se redujeron y también su impacto tributario (Ocampo, 1984b). El monopolio de la sal y el impuesto del degüello de ganado mayor y menor restringían el consumo de esos productos vitales para la nutrición y la salud de la población, y hacían más desigual la distribución del ingreso. La sal era un elemento fundamental en el cuidado de la ganadería, de modo que las políticas de precios eran rechazadas con frecuencia por los ganaderos (Van Ausdal, 2008, 65).

Gráfica 3

Recaudo de aduanas

(Porcentaje del recaudo total)

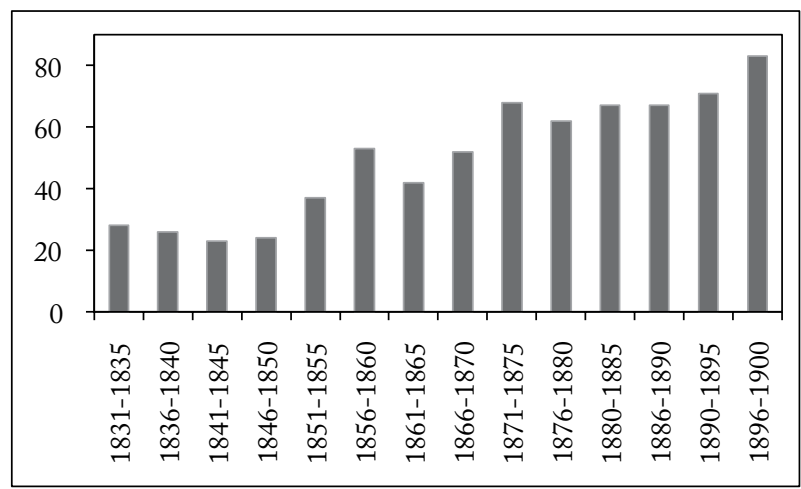

Fuente: Melo (1989).

Los ingresos a duras penas eran suficientes para pagar la administración de los diversos niveles de gobierno, y quedaba muy poco para invertir en educación o desarrollo de la infraestructura. En términos de bienestar social, el cambio más importante en la estructura tributaria fue el paso del gravamen del consumo de tabaco y alcohol bajo el sistema de estancos al del consumo de telas, carne y sal. Vista desde ambos lados de la ecuación fiscal, la distribución del ingreso debió empeorar después de impuestos y de gasto público.

Las principales rentas que recibía el fisco nacional hasta 1850 fueron las de los estancos y los tributos al comercio exterior; además, había un alto grado de centralización política, en particular en la administración fiscal. Desde tiempos virreinales, Bogotá era el centro fiscal que recaudaba impuestos y diezmos en las regiones aledañas y asignaba el gasto, incluidos los situados, como el del puerto amurallado 
de Cartagena. Se había formado una generación de letrados imbuidos por las ideas de la Ilustración que pretendía dirigir a la naciente república, pero muchos de ellos murieron durante la represión de la reconquista. La riqueza concentrada en la capital no era considerable, en comparación con otras ciudades y regiones, lo que cambiaría lentamente a su favor durante el siglo XIX, por cuanto era un centro político, comercial y agropecuario que concentraría economías de escala en población y situación geográfica, fertilidad de la sabana que la rodeaba y clima favorable. Estas ventajas se manifestaron plenamente cuando se integró una red nacional de comunicaciones.

Gráfica 4

Gasto del gobierno central, 1765-1905

(Porcentaje del PIB)

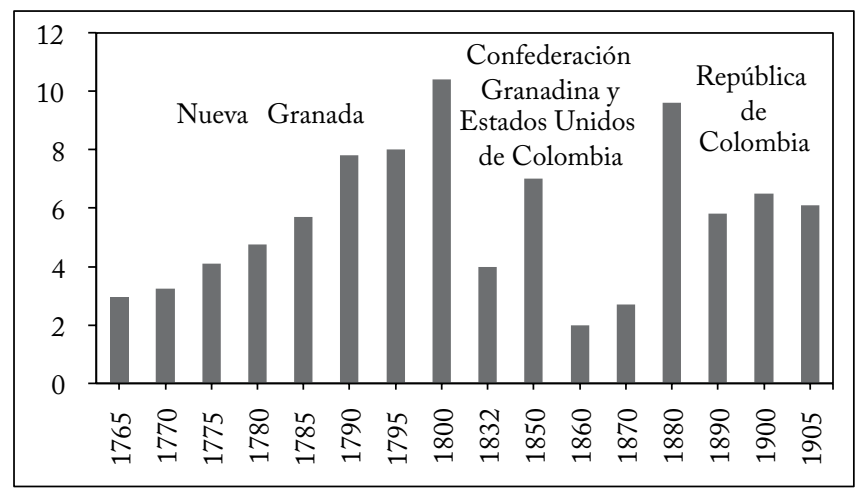

Fuente: Kalmanovitz y López (2009).

En la sociedad neogranadina había una división fundamental entre las élites liberales y comerciales y los sectores conservadores y católicos que se empeñaban en rescatar y preservar el legado hispánico, cuya columna vertebral era el absolutismo. En las circunstancias republicanas, el absolutismo se metamorfoseó en un muy fuerte centralismo político. Estos se enfrentaban a los liberales que abogaban por el positivismo, el cosmopolitismo y el libre cambio, la división de poderes, incluido el poder geográfico, y difundían ideas y propuestas novedosas y democráticas derivadas de corrientes ideológicas de Francia, Inglaterra y Estados Unidos. La élite comercial de Cartagena, por ejemplo, era más liberal que la que se estaba asentando en Santafé de Bogotá, mientras que en Antioquia se establecía un dominio conservador, aunque más pragmático y que optó por el federalismo y por el desarrollo minero y comercial de su territorio. 
Muchas regiones aspiraban a una mayor autonomía política y en especial económica frente a la capital y reclamaban por el abandono a que las sometían las autoridades centrales. Para evitar mayores fragmentaciones territoriales, en 1853 se estableció la Confederación Granadina, antecedente federal de los Estados Unidos de Colombia creados por la Constitución de Rionegro en 1863.

En el contexto latinoamericano, México y Argentina sobresalen como dos de las principales naciones federadas; pero otros países de la región también optaron por este sistema en el siglo XIX, con menos éxito. En el caso mexicano se debate si el federalismo fue copia del modelo estadounidense que se plasmó en la Constitución de 1824 o si fue resultado de la tradición regionalista española, que tiende a tener fuertes elementos centralistas (López, 1992). En el caso argentino, la idea federal se remonta a los años de la Independencia y la formación de la Liga de Países Libres, que se consolidaría con la Constitución de 1853, después de muchos conflictos internos y fragmentaciones políticas. En 1821, los Estados centroamericanos se separaron de México y formaron la República Federal Centroamericana; así mismo, en 1826 Chile se dividió en seis provincias autónomas que después perdieron atribuciones frente al Estado central (Nogueira, 1993). En el caso de México se ha estudiado la relación entre federalismo y concurrencia fiscal, prestando particular atención a la comparación entre el sistema contingente (partida presupuestal que cada Estado debía dar a la federación con base en su población y en su capacidad económica), que se aplicó entre 1824 y 1860, y la época de la contribución ciudadana, entre 1861 y 1943 . Mientras que el primero generó continuos déficit fiscales, la segunda fue más favorable a la consecución de excedentes fiscales (Uthoff, 2004).

Una de las razones para establecer sistemas federales es la descentralización del recaudo de las rentas del erario, que toma en cuenta con más cuidado las particularidades de cada unidad territorial en que se divide el país y logra que la provisión de bienes públicos sea más congruente con las preferencias de los habitantes de cada Estado. En un sistema federal, el ciudadano está más cerca de los políticos que elige y del gobierno, y puede ejercer mejor control sobre ellos. Al mismo tiempo, puede influir en el gasto público, formando un círculo virtuoso de tributación de consenso que financia las obras y satisface las preferencias de la mayoría. En el centralismo, tiende a suceder lo contrario: los mandatarios dependen poco de los ciudadanos, los suelen violentar con sus pretensiones tributarias y el gasto es desatinado, expuesto a la corrupción y al despilfarro. 
Es usual que el centralismo decrete impuestos sin aprobación del legislativo y violente así la regla de oro del liberalismo político de que la representación es lo que da legitimidad a la tributación. Los ciudadanos entonces ejercen resistencia en forma de elusión y evasión de los impuestos decretados en forma centralizada y arbitraria o se desentienden de la forma como se financia el Estado que supuestamente los protege.

En el caso colombiano, la tendencia a captar la mayor parte de la tributación con el arancel a las importaciones reflejaba la inclinación política a recurrir a una carga relativamente invisible para los ciudadanos y conseguir el apoyo de sectores manufactureros o artesanales que se beneficiaban con la protección de la producción local. El rechazo de la tributación directa y del impuesto a la propiedad reflejaba, a su vez, las grandes prerrogativas que adquirieron los criollos, aun bajo el dominio español, por las mercedes de grandes extensiones de tierra por parte del rey, consideradas como un privilegio concedido graciosamente por el Estado ahora republicano, que las distribuyó en forma más desordenada y general que la Corona, y exentas de toda obligación. Si durante la Colonia los terratenientes más observantes pagaban el diezmo para sostener el culto, con la República dejaron de hacerlo después de la manumisión de manos muertas de 1863. La actitud de negarse a sostener el Estado se extendió a las corporaciones, bien fuesen la Iglesia o las comunidades indígenas, y tomó fuerza como tradición que perdura hasta hoy.

\section{INGRESOS DE LOS ESTADOS}

A mediados del siglo XIX el gobierno de la república neogranadina, como el de muchos otros países latinoamericanos, emprendió importantes reformas para reducir el peso del legado colonial en sus instituciones, cuyo éxito relativo se manifestó en el crecimiento económico de las nacientes repúblicas:

En la mayoría de los casos el proceso comenzó con la eliminación de los monopolios del Estado (p. ej., el del tabaco), los fueros de los militares y de la iglesia (excepciones a la justicia civil y la jurisdicción penal) y otros privilegios, como el amplio conjunto de impuestos, tasas y derechos arcaicos de propiedad (que comprendían propiedades de manos muertas a favor de la iglesia y la esclavitud, entre otras) (Coatsworth y Taylor, 1998, 23).

Algunas de las reformas que impulsaron los gobiernos de la Nueva Granada y la Confederación Granadina se resumen en el cuadro 1. 
Cuadro 1

Leyes relevantes segunda mitad siglo XIX

\begin{tabular}{ll}
\hline Ley del 20 de abril de 1850 & Descentralización de recursos \\
\hline Ley del 14 de mayo de 1851 & Eliminación del fuero eclesiástico \\
\hline Ley del 21 de mayo de 1851 & Liberación de los esclavos \\
\hline Ley del 30 de mayo de 1851 & Libertad de imprenta \\
\hline Ley del 15 de junio de 1853 & Matrimonio civil y divorcio \\
\hline Decreto del 9 de septiembre de 1861 & $\begin{array}{l}\text { Secularización, tuición de cultos, desamortización de bienes } \\
\text { de manos muertas }\end{array}$ \\
\hline
\end{tabular}

Las primeras reformas fiscales se emprendieron durante el gobierno del general Mosquera, entre 1845 y 1849, con el propósito de diluir el Estado monopolista, fiscalizador y autoritario, y dar paso a uno que impulsara políticas favorables al desarrollo económico y fomentara las exportaciones y el desarrollo de la libre empresa. E1 estanco del tabaco se liberó parcialmente en 1845, traspasándolo a la firma "Montoya, Sáenz y Cia". La administración de la fábrica tabacalera continuó en manos del Estado, y el monopolio se liberó plenamente en 1850. En ese mismo año se emitió la ley de descentralización de rentas, cuyo ideólogo fue Salvador Camacho Roldán y su principal impulsor, Manuel Murillo Toro. A las provincias se les cedieron los diezmos y los quintos, con la esperanza de que los pudieran eliminar más fácilmente que el gobierno central (Melo, 1989). A los Estados se les transfirieron otras rentas: las de aguardiente, peajes y fundición de oro, mientras que, por el lado del gasto, debían pagar la burocracia, el sistema judicial local, las vías de comunicación regionales y el mantenimiento del culto. Camacho Roldán estimó que "el valor de las rentas cedidas era de un poco más de 530.000 pesos, mientras que los gastos que ahora correspondían a las provincias sumaban unos 435.000 pesos" (Melo, 1989). Estas reformas fueron el primer paso al federalismo colombiano que se estableció trece años después y, en la práctica, determinaron el comportamiento de las finanzas públicas en las tres décadas siguientes. Entre 1851 y 1857 hubo una serie de modificaciones del antiguo sistema de rentas coloniales a uno "más de acuerdo con la justicia i la igualdad de las instituciones republicanas", como dijo Camacho Roldán, quien añadió:

La contribución directa fue inmediatamente ensayada con entusiasmo; pero el cambio de rumbo de las ideas políticas determinado por la administración nacional de 1855 a 1859 i la guerra civil de 1860 a 1863 , pusieron término a esos nobles ensayos (Memoria de Hacienda 1870, XXV).

Con la Constitución de 1863 se consolidó definitivamente el federalismo mediante la división política del país en nueve Estados: Cundinamarca, Antioquia, Magdalena, Santander, Tolima, Bolívar, 
Cauca, Boyacá y Panamá. Esta Constitución surgió como solución a los conflictos que azotaban el territorio desde la Independencia, buscando un punto medio entre el localismo excesivo que provocó las guerras anteriores y el intento de construir una nación y un orden político estables, tarea que estaba pendiente desde la Independencia. La Constitución dio a los Estados mayor autonomía para determinar sus ingresos fiscales y manejar los gastos, y ordenó a las administraciones regionales que establecieran un sistema fiscal productivo que promoviera el desarrollo económico de la región. Además, limitó las funciones específicas del gobierno nacional a campos como la defensa exterior, la educación y la apertura de vías de comunicación.

El fortalecimiento de las finanzas locales fue notable desde 1850, en gran medida debido al auge exportador, cuya volatilidad también las debilitó, de modo que con el inicio de la Regeneración se implantó una férrea centralización política y fiscal. En 1870, Camacho Roldán, orgulloso del comportamiento del sistema que había impulsado, señaló: "La situación fiscal de los Estados ha tomado consistencia; la administración seccional se ha vigorizado; el producto de las rentas es hoy tres veces i media mayor que en $1857 \mathrm{i}$ que en 1863, probablemente también" (Memoria de Hacienda 1870, XXV).

Gráfica 5

Gobierno Nacional, Estados y municipios

(Porcentaje del recaudo total)

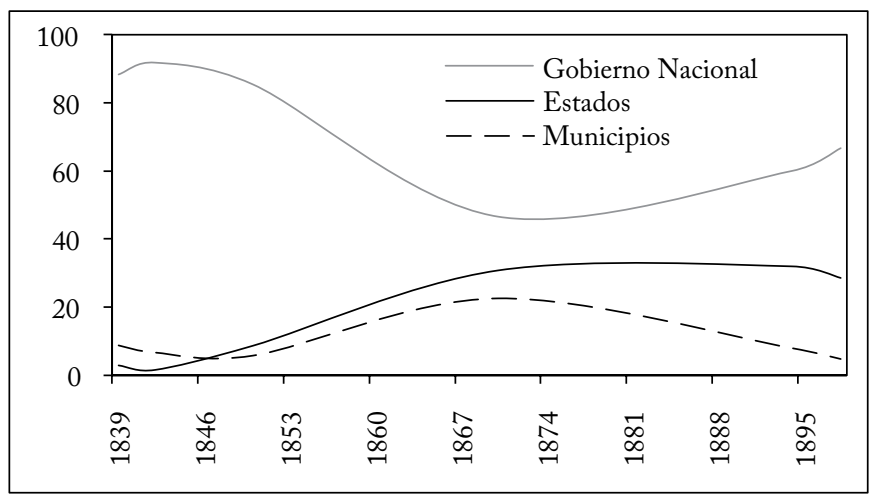

Fuente: Kalmanovitz (2010).

No obstante, los ingresos fiscales de la época apenas eran suficientes para sostener al gobierno que, en general, era pequeño, tanto en el nivel central como en el descentralizado. Los recaudos se vieron afectados por las guerras, en particular por la guerra civil nacional de 1875 a 1876 (la única en ese periodo), y por la necesidad de recurrir 
a financiación interna, y externa en algunos casos, poniendo a prueba la capacidad del gobierno para generar los excedentes necesarios para su amortización.

Sin embargo, la década de 1870 fue el periodo de mayor fortaleza de las finanzas de los Estados (Melo, 1989, y Ocampo, 1984), pues el recaudo alcanzó los dos tercios de las rentas nacionales, "proporción que nunca se volvería a alcanzar” (Ocampo, 1984, 353).

Es notable el progreso de las finanzas del gobierno central y de los Estados soberanos entre 1848 y 1882, año en el que estaba en funciones un gobierno cuyo objetivo era liquidar el experimento federal. Los ingresos de los Estados crecieron a una tasa anual del 8,9\% en ese periodo, de unos magros 228.000 pesos en 1848 a 4.075 .000 en 1882. Por su parte, los ingresos del gobierno central pasaron de 1.360 .600 pesos en 1851 a 8.500 .000 en 1882 , con un crecimiento del $6,1 \%$ anual.

Gráfica 6

Rentas del Gobierno Nacional

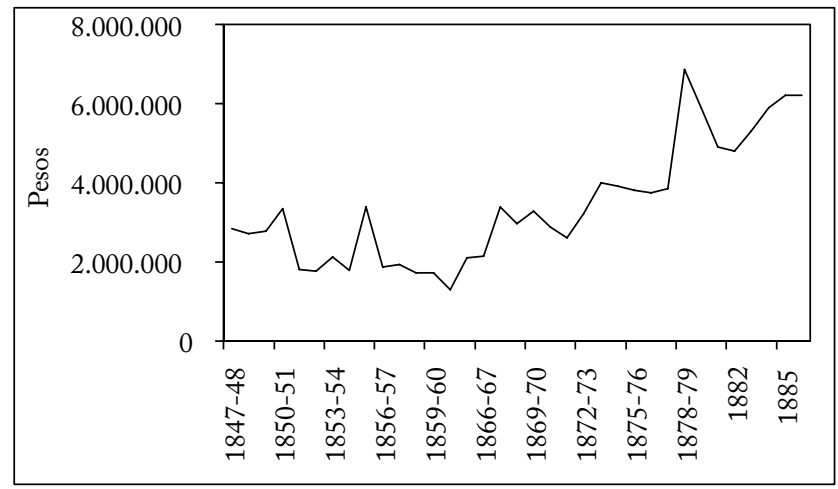

Fuente: Junguito (2010).

Aunque el esfuerzo fiscal por habitante en cada Estados fue bastante desigual, resalta el buen desempeño de Panamá y Bolívar, debido a la actividad comercial de sus puertos en un periodo en que aumentaban las exportaciones. Este indicador muestra que el mayor nivel de recaudo por habitante se logró en 1870 (ver la gráfica 7), que se pudo haber mantenido hasta finales del periodo federal. En comparación con 1848, los colombianos hicieron un mayor esfuerzo fiscal desde 1851, pero sobre todo en el apogeo de la regla federal durante los años setenta. Los tolimenses, caucanos, santandereanos y sobre todo los boyacenses se destacan por su bajo esfuerzo tributario. 
Gráfica 7

Recaudo fiscal por habitante

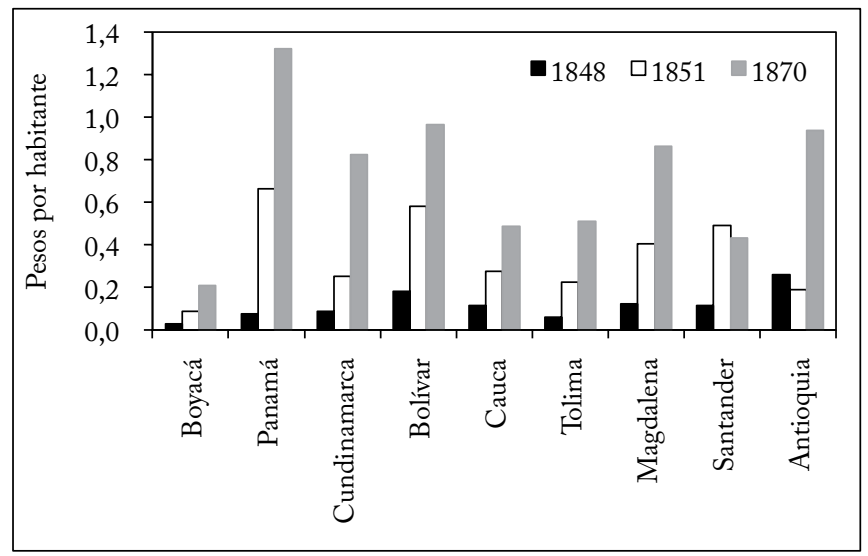

Fuente: Clavijo (1993), Flórez y Romero (2010), Junguito (2010), Melo (2004) e Informes del presidente del Estado de Santander; cálculos propios.

Entre 1848 y 1880 el recaudo aumentó en todos los Estados, y así lo resaltaron los secretarios de hacienda en sus informes a sus presidentes. En la memoria de hacienda sobre el periodo 1868-1869, Camacho Roldán comentó:

Comparando esta situación fiscal con la que tenían las provincias que forman hoi los Estados, en el año de 1851, que siguió inmediatamente a la descentralización de rentas i gastos; medida de que data la vigorización de las secciones y el planteamiento del régimen federal, encontramos resultados lisonjeros en el desenvolvimiento paulatino de este tipo de gobierno (Memoria de Hacienda 1870, XXIII).

El periodo 1881-1883 fue de fuerte déficit en el nivel central; y después de 1884 , la crisis política que surgió con la terminación del primer periodo de gobierno de Rafael Núñez afectó notablemente el recaudo del nivel central, y quizá también el recaudo de los Estados.

En lo que atañe al recaudo promedio de todo el periodo, se pueden identificar tres grupos: en primer lugar, los Estados que alcanzaron altos niveles de recaudo, alrededor de 350 mil pesos anuales, como Antioquia y Cundinamarca; en segundo lugar, los Estados con un nivel de recaudo medio, entre 180 mil y 250 mil pesos, como Cauca, Santander, Panamá y Bolívar; y en tercer lugar, los Estados con bajo recaudo, menos de 100 mil pesos, como Tolima, Boyacá y Magdalena ${ }^{2}$.

${ }^{2}$ Sobre las características fiscales de cada uno de los Estados, Camacho Roldán comentó: "El de Panamá demuestra ser el más obedecido; el de Antioquia el más vigoroso; el de Santander el más sencillo y regular; el de Cauca el más complicado; el de Boyacá el más económico; el de Bolívar el de recursos más 
Gráfica 8

Recaudo promedio de los Estados federales, 1848-1872

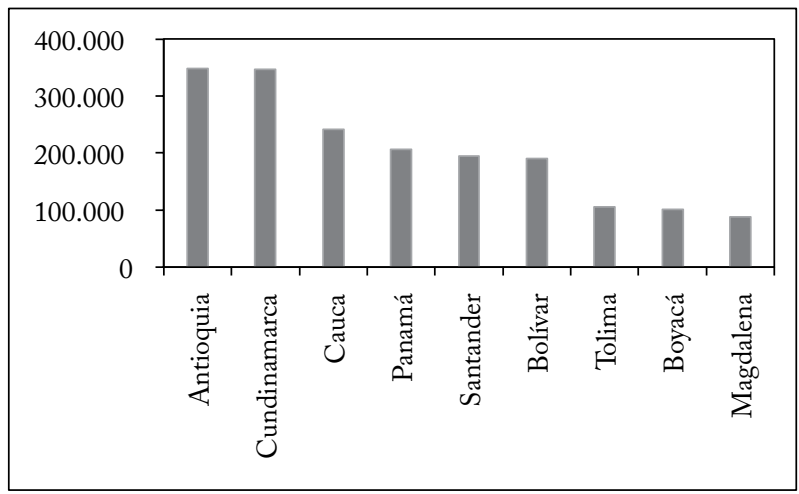

Fuente: Deas (1980), Melo (2007), Clavijo (1993) e Informes del Secretario del Tesoro del Estado Soberano de Santander; cálculos propios.

Santander y Boyacá son dos casos interesantes de estudio. Sus niveles de riqueza eran bastante diferentes pero ambos Estados recurrieron a la tributación directa. Debido a que la información recolectada para estos Estados es más o menos completa, en la gráfica 9 se presentan con más detalle los datos de sus ingresos desde 1848.

Las rentas nominales de los Estados de Boyacá y Santander crecieron al 7\% y al 8\% en promedio durante el periodo que comenzó en ese año y hasta finales del régimen federal en la década de 1880. En ambos, la década de 1870 fue de las de mejor desempeño en términos de ingreso fiscal; en el caso de Santander, 1863 coincide con un cambio estructural del recaudo, y se observa otro salto importante en los primeros años de la década de 1880 . En el caso de Santander se registra una caída del orden del 4\% anual en promedio entre 1863 y 1905 (cuando el ingreso fue de sólo 182.000 pesos), como resultado del proceso de centralización de las rentas que se llevó a cabo durante la Regeneración. 


\section{Gráfica 9}

Ingresos de Boyacá (1848-1886) y Santander (1848-1905)
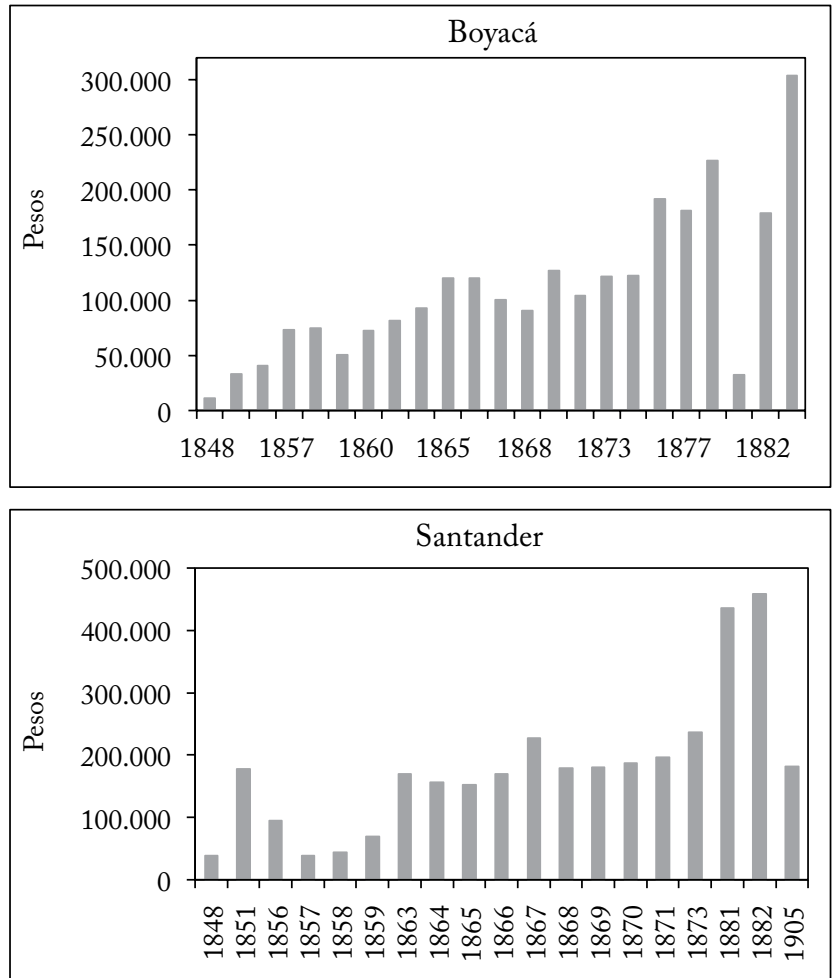

Fuente: Informe del presidente del Estado Soberano de Boyacá a la Asamblea Legislativa en sus sesiones de 1868; Informe del presidente del Estado de Santander a la Asamblea Legislativa de 1870, parte 6, Socorro, Imprenta del Estado, 1870; Deas (1980) y Melo (2007).

La gráfica 10, por su parte, muestra la evolución de los ingresos fiscales de los siete Estados restantes.

Gráfica 10

Ingresos fiscales de los Estados soberanos

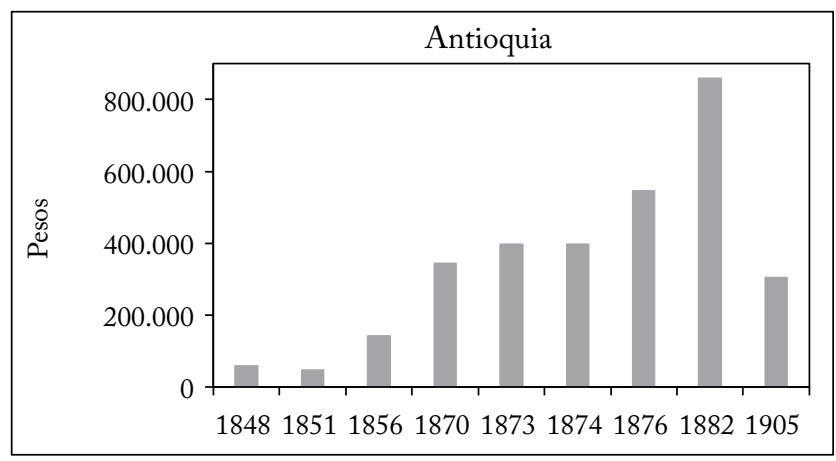

Revista de Economía Institucional, vol. i2, N. ${ }^{\circ} 23$, Segundo Semestre/2oio, pp. I99-228 

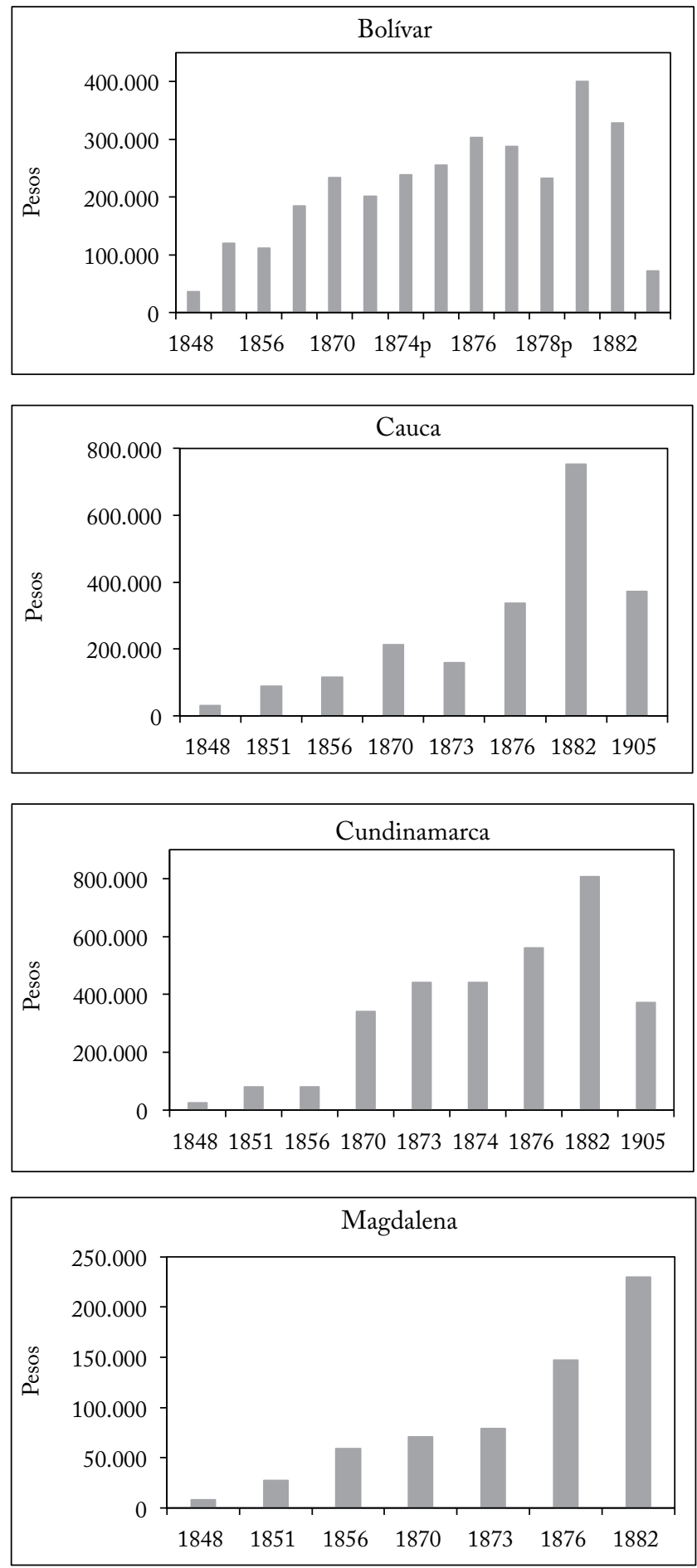

Revista de Economía Institucional, vol. i2, N.o 23 , segundo semestre/2oio, pp. I99-228 

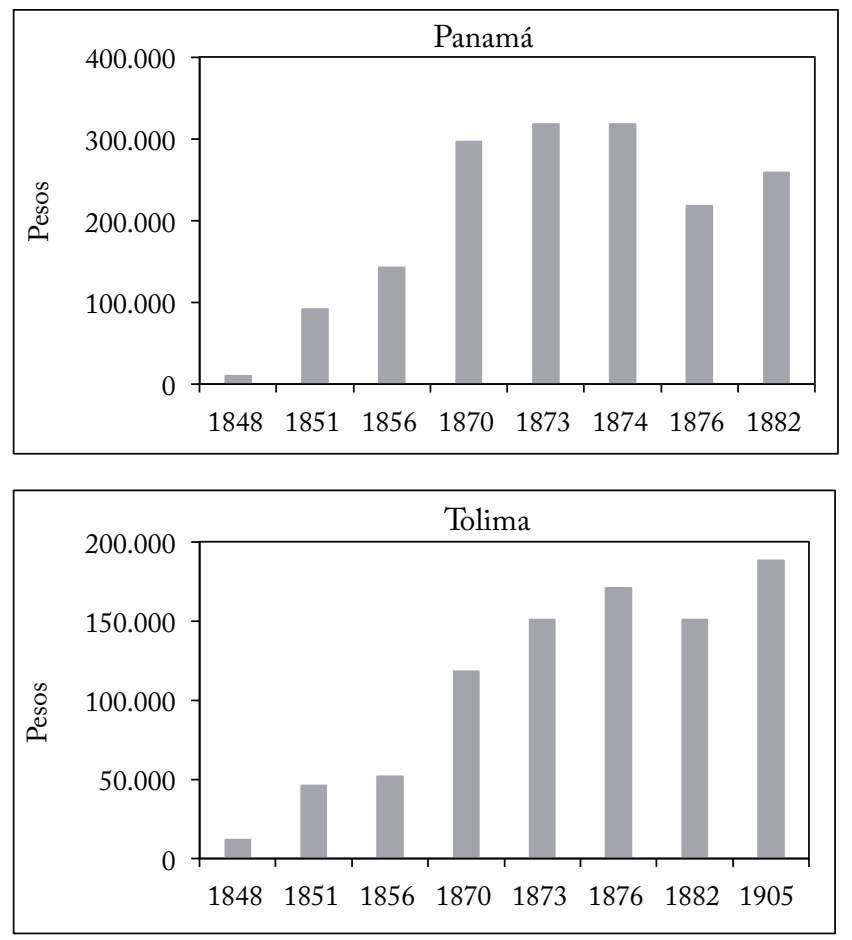

Nota: años seleccionados según disponibilidad de datos: Antioquia, Bolívar, Cauca, Cundinamarca y Tolima (1848-1905), Magdalena y Panamá (1848-1882).

Fuente: Deas (1980), Melo (2007), Clavijo (1993), Informes del Secretario del Tesoro de los Estados soberanos de Santander y Boyacá, y Memoria de Hacienda de 1870. Memoria del Secretario de Hacienda del Estado Soberano del Cauca 1877, Informes de los Secretarios de Hacienda y Gobierno del Estado Soberano del Cauca a la Lejislatura.

En la gráfica 10 se muestra que el recaudo fiscal aumentó en todos los Estados durante el periodo federal: en Antioquia a una tasa promedio anual del 8\%, en Bolívar al 6\%, en Cauca al 7,4\%, en Cundinamarca al 10\%, en Magdalena al 10\%, en Tolima al 7\% y en Panamá al 10\%. También se observa que en Antioquia, Bolívar, Cauca y Cundinamarca hubo una fuerte caída de los recaudos durante el periodo de la Regeneración, a causa de la centralización de rentas. La comparación del recaudo anterior a 1882 con el recaudo fiscal de 1905 da como resultado las siguientes tasas de reducción: Antioquia $-4 \%$, Bolívar $-7 \%$, Cauca $-0,1 \%$ y Cundinamarca $-3 \%$. Solo el Estado de Tolima, ya convertido en departamento, registró un crecimiento, del $1 \%$.

En el Estado del Cauca, las finanzas siempre estuvieron en déficit durante las décadas de 1860 y 1870, aunque se aprecia un aumento sostenido del recaudo. Bartolomé Castillo, en su Informe de Hacienda de 1873, destacó que los ingresos habían aumentado por "el celo y 
actividad que en general han tenido los empleados de hacienda encargados de la recaudación y a la pureza en el manejo e inversión de los caudales públicos".

Entre 1863 y 1882, el recaudo de las rentas caucanas correspondiente a todos sus rubros pasó de 70.000 a 380.000 pesos. Es indudable que se estaba desarrollando un fuerte sentido de pertenencia y que buena parte de la población se estaba sintiendo identificada con su región. Después de 1860 y en gran medida debido a la guerra, muchos sectores de la población, hasta ese momento marginados, fueron incluidos y enaltecidos como ciudadanos sin las restricciones que prevalecieron hasta esa época; además, los campesinos participaban en la producción de artículos importantes como el aguardiente, el tabaco y el cacao (Valencia, 2008).

A pesar de la inexistencia de cálculos de las cuentas del producto departamental durante este periodo, los datos de ingreso fiscal dan una idea muy aproximada del comportamiento de la producción agregada de cada uno de los Estados. Cabe destacar el comportamiento económico de Antioquia y Cundinamarca, que podrían haber sido los Estados más ricos de la federación ${ }^{3}$, como lo corroboran las tasas de crecimiento de la población, las más altas durante el siglo XIX (Flórez y Romero, 2010).

La gráfica 11 muestra conjuntamente la evolución del recaudo de rentas de los nueve Estados federales entre 1848 y 1886. A pesar de que los diferentes Estados tenían un nivel de recaudo similar hacia 1848 , se presentó una marcada divergencia desde 1870, año en el que Cundinamarca y Antioquia lograron recaudos mucho mayores, seguidos muy de cerca por Panamá; esta tendencia se profundizó en los dos primeros Estados en los años siguientes, que correspondieron a un periodo de paz durante gobiernos radicales. A partir de 1874 se observa un rezago notable con respecto a Antioquia y Cundinamarca, lo que corrobora el éxito fiscal de estos dos Estados en el periodo.

En Antioquia, la estabilidad relativa que logró el gobierno conservador de Pedro Justo Berrío, que permaneció nueve años en la presidencia del Estado, hasta 1873, sentó las bases del desarrollo

3 Camacho Roldán señaló la importancia de Cundinamarca y Tolima como dos centros económicos importantes, pero fuertemente afectados por las guerras: "son quizá los que cuentan, en el gran valor de las producciones, en la riqueza acumulada en el uno i la fácil acumulación en el otro, i en la condición homogénea de sus producciones, mas elementos que ningún otro para darse una buena organización i entrar en una vía de orden i prosperidad. La concentración de todas las agitaciones de la política nacional en la capital del uno i la importancia estratégica en los tiempos de guerra civil del otro, son quizás las causas determinantes de la debilidad en que han vivido sus gobiernos hasta este día" (Memoria de Hacienda 1870, XVI). 
económico posterior, basado en el impulso a la iniciativa privada que dio lugar a la modernización de la minería del oro. A esto se sumó el desarrollo de la educación, en el que, por cierto, la Iglesia tuvo un papel importante y le dio una orientación relativamente pragmática.

Por su parte, el recaudo de departamentos costeros como Panamá, Bolívar y Magdalena no fue sobresaliente, aunque en los dos últimos tuvo un crecimiento notable desde 1873 hasta comienzos de los ochenta (salvo la caída del recaudo de Bolívar entre 1786 y 1788). Esto quizá obedezca a la mayor inserción en el comercio internacional que tuvo el país en la segunda mitad del siglo XIX, que pudo beneficiar el comercio interno de estos Estados, ya que como se recordará el recaudo de impuestos al comercio exterior lo ejercía el Estado central.

Gráfica 11

Ingresos fiscales por Estado, 1848-1876

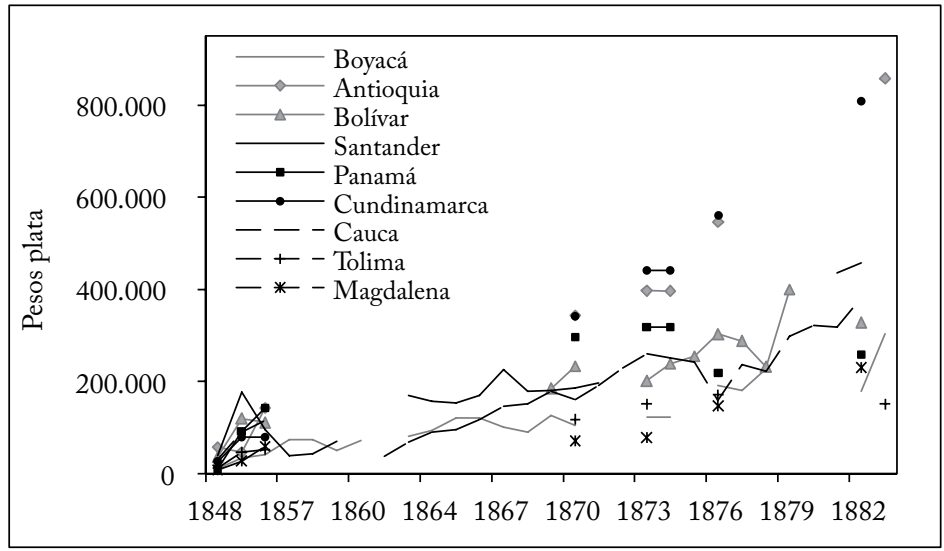

Nota: todos los ingresos son efectivos, menos en el caso de Bolívar, donde se recurrió al presupuesto de rentas para los años 1869, 1874, 1875, y 1877-1879.

Fuente: Deas (1980), Melo (2007), Clavijo (1993), Informes del Secretario del Tesoro de los Estados soberanos de Santander y Boyacá, Memoria de Hacienda de 1870, Memoria del Secretario de Hacienda del Estado Soberano del Cauca 1877, Informes de los Secretarios de Hacienda y Gobierno del Estado Soberano del Cauca a la Lejislatura, Informe del presidente del Estado Soberano de Boyacá a la Asamblea Legislativa en sus sesiones de 1868, Informe del presidente del Estado de Santander a la Asamblea Legislativa de 1870, parte 6, Socorro, Imprenta del Estado, 1870.

La gráfica 12 y el cuadro 2 muestran cierta tendencia a la convergencia del recaudo de los Estados, en especial la que en la literatura se conoce como convergencia beta, que indica que los Estados con menores niveles de recaudo en 1848 tuvieron un mayor crecimiento de sus ingresos fiscales durante el periodo federal. Más que una coincidencia, 
la convergencia se podría explicar al menos por dos causas: en primer lugar, por las mejoras en la eficiencia del recaudo; en segundo lugar, porque el federalismo pudo favorecer el crecimiento económico en los Estados y, con ello, la convergencia regional. Se puede intuir que el fuerte aumento de las exportaciones durante los diferentes ciclos de productos tuvo un impacto nacional, de modo que todas las regiones tendieron a beneficiarse y, por ello, aumentaron sus ingresos; y que el colapso del tabaco, el añil, el índigo, etc. fue amortiguado por la constancia de las exportaciones de oro y una creciente exportación de cuero y de carne, y no menos de café.

\section{Gráfica 12}

Convergencia del recaudo fiscal de los Estados soberanos

Tasa de crecimiento $1848-1886$

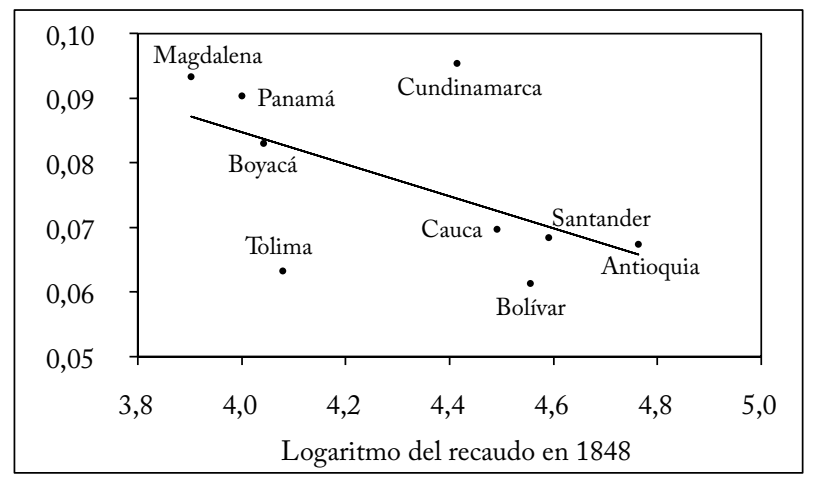

Fuente: Datos de la gráfica 10, cálculos propios.

Cuadro 2

Estimaciones de la convergencia beta

\begin{tabular}{lccrr}
\hline $\mathrm{R}^{2}=0,4$ & Coeficientes & Error típico & \multicolumn{1}{c}{ Estadístico t } & Probabilidad \\
\hline Intercepto & 5,32084089 & 0,55616623 & 9,56699748 & $2,8622 \mathrm{E}-05$ \\
Beta $^{* * * *}$ & $-13,0675437$ & 7,13219231 & $-1,83219172$ & 0,10959265 \\
\hline
\end{tabular}

Fuente: Cálculos de los autores.

En cuanto a la primera explicación, se debe tener en cuenta que la organización fiscal difería entre Estados. Mientras que unos optaron por la contribución directa (Santander, Boyacá, Cauca, Tolima y Cundinamarca), otros mantuvieron un sistema fiscal que gravaba la producción y el consumo, en el que se destacaban los derechos de consumo y degüello, y la renta de licores (Antioquia, Panamá, Magdalena y Bolívar). Pero, como se verá más adelante, la contribución indirecta era la principal fuente de recaudo en todos los Estados, incluso en los que optaron por la contribución directa. En todo caso, 
es notable el mayor esfuerzo fiscal per cápita que cada uno de ellos hizo en el periodo comprendido entre 1851 y 1870.

En cuanto a la segunda explicación, es importante considerar que el gasto público pudo contribuir a mejorar los caminos y, así, a profundizar la especialización regional y mejorar la productividad y el crecimiento; en algunos casos, como el de Antioquia, la instrucción pública pudo tener un impacto sobre el mayor crecimiento económico que a todas luces estaba generando la colonización del occidente del Estado soberano. Habría entonces una relación causal entre la riqueza del Estado y el recaudo tributario,

Los derechos al consumo consistían en una serie de tasas que a veces se aplicaban a productos locales y a veces a productos importados; eran un impuesto al consumo que tendía a ser regresivo y que en el caso del aguardiente se convertía en renta al subastar a un empresario privado el monopolio que quedó en manos de cada Estado soberano.

La contribución directa fue el tercer rubro en importancia dentro del recaudo agregado de los Estados soberanos, con un 17\%, algo que no había recibido la importancia que adquirió en estos años de federalismo pleno, como lo fueron 1873-1874.

En términos generales, el recaudo fiscal fue regresivo, debido a que dependía fundamentalmente de rentas distintas a las que gravaban el ingreso, incluso en los Estados que establecieron la tributación directa. La tasa de tributación era muy baja (en Santander era del 0,3\% sobre el patrimonio). Y debido a que los deficientes sistemas de catastro y de registro de la riqueza llevaban a que las administraciones fiscales de cada Estado subestimaran el ingreso gravable de sus habitantes.

Cuadro 3

Composición del ingreso por Estado, 1873-1874

(Porcentaje)

\begin{tabular}{lrrrrrrrrrr}
\hline $\begin{array}{l}\text { Naturaleza de las rentas y } \\
\text { contribuciones }\end{array}$ & $\mathrm{a}$ & $\mathrm{b}$ & $\mathrm{c}$ & $\mathrm{d}$ & $\mathrm{e}$ & $\mathrm{f}$ & $\mathrm{g} *$ & $\mathrm{~h}$ & $\mathrm{i}$ & Total \\
\hline Aguardientes y licores & 44,2 & 7,2 & 23,8 & 10,7 & 0,1 & 13,6 & & 53,5 & 13,2 & 18,7 \\
Contribución directa & & 16,8 & 40,1 & & 18,2 & & 35,8 & 14,9 & 29,1 & 16,9 \\
Correos & 0,5 & & & 0,2 & & & & & 0,5 & 0,2 \\
Casas de moneda & 4,0 & & & & & & & & & 0,8 \\
Derecho de consumo & 22,5 & 5,2 & & 41,7 & 17,0 & 9,4 & & & & 11,8 \\
Derecho de degüello & 14,1 & 42,1 & 8,2 & 12,6 & 13,6 & 26,2 & 23,6 & 23,2 & 29,1 & 20,2 \\
Impuesto de minas & 1,5 & & & & & & & & 0,8 & 0,3 \\
Impuesto sobre mortuorias & 1,4 & 0,8 & & & 1,4 & & & & 4,6 & 1,0 \\
Impuestos e ingresos varios & 6,8 & 11,9 & 0,1 & 12,6 & 0,7 & 5,4 & 14,2 & 5,1 & 4,0 & 6,7 \\
Intereses de renta nominal & & & & 0,3 & & & & 3,4 & & 0,4
\end{tabular}




\begin{tabular}{lccrrrrrrr} 
Peajes & & & & 5,1 & 36,3 & & & 5,3 & 8,4 \\
Papel sellado & 3,1 & 5,5 & 9,8 & 12,6 & 5,4 & 2,7 & 3,8 & 9,3 & 5,1 \\
Pecuaria de cría & 0,0 & & & & & & 12,6 & & 1,9 \\
Derechos de registro y anotación & 1,8 & 3,0 & 1,6 & 2,5 & 2,7 & 1,3 & 2,2 & 4,0 & 2,1 \\
Subvención nacional & & & & & & 31,7 & 7,9 & & 2,4 \\
Salinas & & 6,9 & 16,4 & 1,6 & 4,5 & 9,7 & & & 3,1 \\
\hline
\end{tabular}

a. Antioquia, b. Bolívar, c. Boyacá, d. Cauca, e. Cundinamarca, f. Magdalena, g. Panamá, h. Santander, i. Tolima.

*Datos de 1874.

Fuente: Deas (1980), cálculos propios.

Boyacá fue el único Estado donde la tributación directa tuvo relativo éxito. Como muestra el cuadro 3, en 1874 el ingreso por contribución directa correspondía al 40\% del total, y en 1877 ascendía al 60\% (Informe del Secretario de Hacienda al presidente del Estado de Boyacá 1877, 77). Esto contrasta con la pobreza fiscal de dicho Estado en comparación con los otros ocho miembros de la federación.

En todo caso, los impuestos más importantes en la mayoría de Estados eran indirectos, y la participación de éstos fue alta y creciente durante el periodo. En 1882 el monopolio del aguardiente era una fuente central de ingresos en Antioquia y Santander, sobre todo en Antioquia, cuyo recaudo por este concepto fue de 435.000 pesos, el más alto de toda la República (Melo, 2007). Bolívar, Santander y Panamá eran los principales recaudadores del impuesto de degüello, que gravaba a la proteína más importante en el consumo de la población. El monopolio de la sal también imponía un fuerte castigo para sus magros ingresos y puede haber influido en la alta incidencia de una enfermedad endémica, el coto. Y como se dijo antes, la sal era un ingrediente importante en la alimentación del ganadero, de modo que su alto precio también debió incidir en el precio de la carne. El peaje o pontazgo fue instaurado por todos los Estados; en la práctica funcionaba como un sistema de aduanas interno, reforzado con la obligación, para algunos productos, de pagar derechos de consumo en Estados distintos al de su lugar de origen. Esto fue motivo de tensiones frecuentes durante el régimen federal, y observadores de la época lo consideraron como un obstáculo para consolidar el mercado interno del país y, por tanto, como una barrera al crecimiento económico de largo plazo (Melo, 2007).

Lo anterior deja entrever la debilidad del gobierno central para establecer el orden, y el desconocimiento de su papel de árbitro en el sistema federal. A esto se sumaban los desajustes fiscales derivados de las guerras que libraron los Estados, como en el caso de Santander donde comenzaron las guerras de 1860 y 1885. 
En 1871, el Poder Ejecutivo llamó de nuevo la atención del Congreso sobre este grave asunto:

Las disposiciones vijentes sobre órden público son incompatibles con la República federal, cuyo objeto es hacer hombres libres en Estados libres; destruyen la nocion del derecho de las mayorías i establecen como doctrina política que el sable es la verdadera fuente del poder; enjendran el fraude en apoyo de la fuerza i alejan toda esperanza de alternabilidad pacifica de los partidos en el Gobierno; obligan a los Estados a gastar gran parte de sus recursos en sostener fuerza permanente; mantienen el país en incesante alarma i aniquilan la industria haciéndole perder toda confianza en la seguridad; hacen necesaria la intervencion de unos Estados en las cuestiones de los otros con el fin de proveer a su propia seguridad, i son oríjen de continuas dificultades entre el Gobierno jeneral i los de las secciones; en fin, tienden directamente a sacar la influencia política de las mayorías pacíficas i laboriosas, para colocarla en manos de las facciones que saben adueñarse del poder. E1 Gobierno jeneral debe garantizar el orden o borrar esta palabra del escudo nacional, porque parece una burla que la nacion que ostenta órden en sus armas sea precisamente la unica que no lo sabe conservar; i al borrar la palabra órden debe suprimir tambien la palabra libertad, porque sin órden no hai derechos para los individuos ni soberania para el pueblo.

Los problemas fiscales no fueron entonces la causa de la crisis del sistema federal, puesto que este fue el periodo de mayor fortalecimiento de las finanzas públicas, centrales y descentralizadas, del siglo XIX. La crisis del sistema fue resultado de la falta de reglas que garantizaran los derechos de la oposición y del excesivo localismo que la Constitución de 1863 no logró contrarrestar, puesto que el débil poder central hizo imposible que surgiera un orden político estable, producto del consenso entre todas las élites, que llevara a una paz estable sobre la cual se pudiera construir un orden económico más favorable para el desarrollo.

\section{UNA NOTA SOBRE LOS GASTOS}

Un breve análisis de los datos de gasto fiscal por Estado indica que las erogaciones eran congruentes con el recaudo, puesto que la clasificación de los Estados en función del ingreso anterior se ajusta a la clasificación en función de los gastos ${ }^{4}$ : Antioquia y Cundinamarca con altos niveles de gasto (entre 400 mil y 500 mil pesos); Cauca, Panamá, Santander y Bolívar con niveles medios de gasto (alrededor de 300 mil pesos), y Tolima, Boyacá y Magdalena con los niveles de gasto más bajos (de 100 mil a 150 mil pesos). El gobierno nacional y los gobiernos locales nunca se ganaron la confianza de los inversionistas porque incumplían repetidamente sus compromisos,

\footnotetext{
${ }^{4}$ En el caso del gasto, el número de años considerado es menor que el de la muestra utilizada para calcular los ingresos promedio.
} 
lo que impidió crear un mercado de capitales, y primero de deuda pública, que sirviera de guía a un mercado de deuda privada. Por ello no surgió un sistema financiero profundo en el país, apalancado por inversionistas extranjeros, lo que obligaba a un equilibrio relativo de las finanzas públicas, aunque se recurría a la emisión de deuda interna que adquirían algunos agiotistas, y en las guerras, a préstamos forzosos o expropiaciones arbitrarias (Rojas, 2004). No obstante, después que los gobiernos conservadores descubrieron el poder de la emisión de papel moneda como instrumento fiscal, se excedieron cada vez más, al principio provocando una inflación moderada, que luego terminaría en llamaradas hiperinflacionarias para financiar la Guerra de los Mil Días.

Gráfica 13

Gasto promedio de los Estados federales, 1870-1876

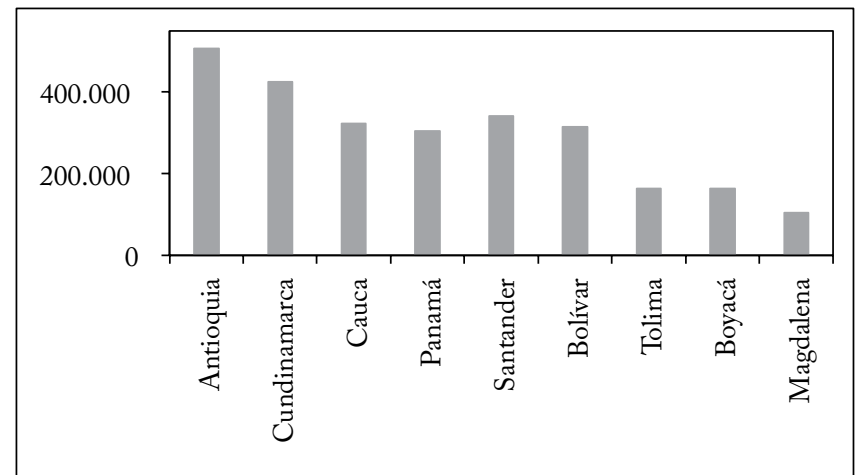

Fuente: Deas (1980), Melo (2007), Clavijo (1993) e Informes del Secretario del Tesoro del Estado Soberano de Santander; cálculos propios.

Como ya se señaló, el déficit del gobierno central fue casi nulo hasta la década de 1880, así como el de los Estados soberanos, cuyos déficit en términos generales fueron cercanos a cero o muy bajos. A lo largo del periodo, Tolima, Cundinamarca y Magdalena tuvieron déficit bajos, y algún superávit. El balance fiscal de los Estados entre 1876 y 1877, periodo para el que se tienen datos relativamente completos, de gastos e ingresos, muestra que la mayoría de los Estados tenían sus finanzas en rojo, excepto Cundinamarca y Magdalena, quizá a causa de la única guerra civil nacional del periodo. 


\begin{tabular}{|c|c|c|c|}
\hline Estado & Rentas & Gasto & Balance \\
\hline Antioquia & 546.200 & 611.700 & -65.500 \\
\hline Bolívar & 303.114 & 415.875 & -112.761 \\
\hline Boyacá & 191.937 & 232.814 & -40.877 \\
\hline Cauca & 336.650 & 404.072 & -67.422 \\
\hline Cundinamarca & 560.194 & 557.730 & 2.464 \\
\hline Magdalena & 146.936 & 146.520 & 416 \\
\hline Panamá & 218.095 & 250.000 & -31.905 \\
\hline Santander & 344.671 & 534.389 & -189.718 \\
\hline Tolima & 170.904 & 249.397 & -78.493 \\
\hline Total Estados & 2.818 .701 & 3.402 .496 & -583.795 \\
\hline
\end{tabular}

Fuente: Junguito (2010).

Sin embargo, en la década de 1880 aumentaron los requerimientos de gasto en todos los niveles de la administración pública, debido a las inversiones en obras públicas y ferrocarriles, lo que llevó a que los Estados recurrieran cada vez más al fisco nacional (Ocampo, 1984), generando el profundo déficit del gobierno central de 1880-1883. Las transferencias y auxilios nacionales se interpretaron como "una reaparición del centralismo, y un debilitamiento de la energía local que se había tratado de promover con la descentralización de mediados de siglo" (Ocampo, 1984, 355).

\section{CONCLUSIONES}

En el periodo federal colombiano se fortalecieron las finanzas públicas en todos los niveles de la administración, en especial en la década de 1870. Se modernizó el sistema tributario: a nivel nacional, dependiente de las tarifas aduaneras, y a nivel de los Estados, de las contribuciones indirectas, con algunos ensayos de impuestos a la propiedad que no fructificaron.

Fue entonces un periodo de ruptura definitiva con las instituciones fiscales heredadas del periodo colonial, y de búsqueda de un orden político que permitiera el desarrollo económico del país, algo que no se logró del todo. El andamiaje político federal que se construyó era endeble y fue destruido por las fricciones entre liberales y conservadores.

Los datos indican un fortalecimiento de las finanzas públicas del nivel central y de los Estados, con pocos episodios de déficit, tendencia que se revirtió en el primer quinquenio de los ochenta. El buen comportamiento del recaudo deja entrever también un buen desempeño económico de los Estados soberanos en ese periodo, en particular de Antioquia y Cundinamarca. 
Mientras que el recaudo del gobierno central dependía de los impuestos al comercio exterior y del monopolio de las salinas, el de los Estados se basaba en impuestos de degüello, derechos de consumo y renta de licores. A pesar de que muchos Estados acudieron a la tributación directa, esta se debilitó y el sistema fiscal fue regresivo.

Las reformas sucesivas de la década de 1850, que establecieron el sistema federal en Colombia y culminaron con la Constitución de 1863, se pueden interpretar como la búsqueda de un nuevo orden político nacional que cuarenta años después de la Independencia era débil o casi inexistente a causa de frecuentes guerras civiles. Aunque en su momento la regla federal obtuvo relativo consenso, no fue suficientemente incluyente para que todas las élites se sintieran representadas; la competencia política tendió a restringirse, el sistema judicial a sesgarse y faltó flexibilidad o escenarios de negociación para resolver pacíficamente las causas de los conflictos. En especial, se fortalecieron los Estados en detrimento de la capacidad del gobierno central para actuar con la fuerza suficiente y ser árbitro justo del sistema. Esto ocasionó dos guerras civiles nacionales, la de 1875 y la de 1885; esta última clausuró el periodo federal y liquidó la descentralización fiscal, remplazándola por un centralismo excesivo, sin derechos para la oposición; restableció además el vínculo entre el Estado y la Iglesia Católica. Centralismo a ultranza y dogmatismo religioso fueron efectivamente las bases programáticas de los gobiernos de la Regeneración.

\section{REFERENCIAS BIBLIOGRÁFICAS}

1. Archivo Departamental de la Gobernación de Boyacá. Informe del presidente del Estado Soberano de Boyacá a la Asamblea Legislativa en sus sesiones de 1868, Tunja, Imprenta Torres Hnos. y Cía., 1886.

2. Archivo Departamental de la Gobernación de Boyacá. Informe del presidente del Estado 1858-1868, Tunja, Imprenta Torres Hnos., 1868.

3. Archivo Departamental de la Gobernación de Boyacá. Informe del Secretario de Hacienda al presidente del Estado de Boyacá 1877, Tunja, Imprenta Torres Hnos. y Cía., 1877.

4. Biblioteca Nacional. Informe del presidente del Estado de Santander a la Asamblea Legislativa de 1870, parte 6, Socorro, Imprenta del Estado, 1870.

5. Calderón R., C. Elementos de hacienda pública, Bogotá, Imprenta de la Luz, 1911.

6. Church, D. Santander siglo XIX: cambios socioeconómicos, Bogotá, Valencia Editores, 1984.

7. Clavijo O., H. "Monopolio fiscal y guerras civiles en el Tolima, 18651899”, Boletín Cultural y Bibliográfico 30, 32, 1993. 
8. Coatsworth, J. H. y A. M. Taylor, comp. Latin America and the world economy since 1800, Cambridge, Harvard University, 1998.

9. Cruz S., A. "Economía y hacienda pública", Historia extensa de Colombia, vol. XV, t. I, Bogotá, Ediciones Lerner, 1965.

10. Deas, M. “Los problemas fiscales en Colombia, durante el siglo XIX”, J. A. Ocampo, comp., Ensayos sobre historia económica colombiana, Bogotá, Fedesarrollo, 1980.

11. Flórez, C. E. y O. Romero. "La demografía de Colombia durante el siglo XIX”, A. Meisel y M. T. Ramírez, eds., Economía colombiana del siglo XIX, Bogotá, Fondo de Cultura Económica y Banco de la República, 2010.

12. Galindo, A. Estudios económicos y fiscales, Bogotá, Anif-Colcultura, 1978.

13. Estado Soberano del Cauca. Informe del Secretario de Gobierno del Estado Soberano del Cauca a la Lejislatura 1881, Popayán, 1881.

14. Estado Soberano del Cauca. Informe del Secretario de Hacienda del Estado Soberano del Cauca a la Lejislatura 1869, Popayán, 1869.

15. Estado Soberano del Cauca. Informe del Secretario de Hacienda del Estado Soberano del Cauca a la Lejislatura 1871, Popayán, 1871.

16. Estado Soberano del Cauca. Informe del Secretario de Hacienda del Estado Soberano del Cauca a la Lejislatura 1872, Popayán, 1872.

17. Estado Soberano del Cauca. Informe del Secretario de Hacienda del Estado Soberano del Cauca a la Lejislatura 1873, Popayán, 1873

18. Estado Soberano del Cauca. Informe del Secretario de Hacienda del Estado Soberano del Cauca a la Lejislatura 1875, Popayán, 1875.

19. Estado Soberano del Cauca. Informe del Secretario de Hacienda del Estado Soberano del Cauca a la Lejislatura 1883, Popayán, 1883.

20. Estado Soberano del Cauca. Informe del Secretario de Hacienda del Estado Soberano del Cauca a la lejislatura en sus sesiones ordinarias de 1873 (Bartolomé Castillo), Popayán, Imprenta del Estado, 1873.

21. Estado Soberano de Santander. Informe del presidente del Estado de Santander a la Asamblea Legislativa de 1870 [Solón Wilches], Socorro, Imprenta del Estado, 1870.

22. Estado Soberano de Santander. Informe del superintendente de la instrucción pública del Estado de Santander a la asamblea legislativa de 1875, Socorro, Imprenta del Estado, 1875.

23. Estado Soberano de Santander. Leyes y decretos espedidos por la Asamblea del Estado 1865, Socorro, Imprenta del Estado, 1865.

24. Estado Soberano de Santander. Informe del Encargado de la Presidencia del Estado de Santander a la Asamblea Constituyente de 1859, Bucaramanga, Imprenta de Zapata Hermanos, 1859.

25. Estado Soberano de Santander. Informe del Jefe Superior del Estado de Santander a la Asamblea Lejislativa [M. Murillo], Bucaramanga, Imprenta de Zapata Hermanos, 1858.

26. Estado Soberano de Santander. Informe del presidente de Santander a la Asamblea Constituyente en sus sesiones de 1866 [José M. Villamizar G.], Socorro, Imprenta de I. Céspedes, 1866.

27. Estado Soberano de Santander. Informe del presidente de Santander a la Asamblea del Estado, en sus sesiones ordinarias de 1863 [Eustorgio Salgar], Socorro, Imprenta de I. Céspedes, 1863. 
28. Estado Soberano de Santander. Informe del presidente del Estado, Bucaramanga, Imprenta del Estado, 1873.

29. Estado Soberano de Santander. Informe del presidente del Estado sobre Ramo de Santander a la Asamblea Legislativa de 1872, Socorro, Imprenta del Estado, 1872.

30. Estado Soberano de Santander. Mensaje del presidente de Santander a la Asamblea legislativa de 1882 y memorias de los secretarios de Gobierno y Hacienda, Socorro, Imprenta del Estado, 1882.

31. Jaramillo, J., A. Meisel y M. Urrutia. "Continuities and Discontinuities in the Fiscal and Monetary Institutions of New Granada 1783-1850", Borradores de Economía 74, 1997.

32. Jaramillo, R. L. y A. Meisel. "Más allá de la retórica de la reacción, Análisis económico de la desamortización en Colombia, 1861-1888”, A. Meisel y M. T. Ramírez eds., Economía colombiana del siglo XIX, Bogotá, Fondo de Cultura Económica y Banco de la República, 2010.

33. Junguito, R. "Las finanzas públicas en el siglo XIX", A. Meisel y M. T. Ramirez eds., Economía colombiana del siglo XIX, Bogotá, Fondo de Cultura Económica y Banco de la República, 2010.

34. Kalmanovitz S. y E. López R. Las cuentas nacionales de Colombia en el siglo XIX, Bogotá, Universidad Jorge Tadeo Lozano, 2009.

35. Kalmanovitz, S. "La idea federal en Colombia durante el siglo XIX", R. Sierra, ed., El radicalismo colombiano del siglo XIX, Bogotá, Universidad Nacional de Colombia, 2006.

36. Kalmanovitz, S. Nueva historia económica de Colombia, Bogotá, Taurus y Universidad Jorge Tadeo Lozano, 2010.

37. López G., F. Historia de la hacienda y el tesoro en Colombia, Bogotá, Banco de la República, 1992.

38. McGreevey, W. P. Historia económica de Colombia 1845-1930, Bogotá, Ediciones Tercer Mundo, 1975.

39. Melo, J. O. “Del federalismo a la Constitución de 1886", Nueva Historia de Colombia, Bogotá, Editorial Planeta, 1989.

40. Melo, J. O. "Las vicisitudes del modelo liberal 1850-1899", J. A. Ocampo, ed., Historia económica de Colombia, Bogotá, Planeta, 2007.

41. Memoria del Secretario de Hacienda del Estado Soberano del Cauca, 1877.

42. Nogueira, H. "E1 régimen jurídico constitucional del gobierno y la administración colonial y regional en Chile", Simposio Internacional sobre derecho del Estado, Bogotá, Universidad Externado de Colombia, 1993.

43. Ocampo, J. A. "Centralismo, descentralización y federalismo en la historia colombiana”, J. A. Ocampo y S. Montenegro, eds., Crisis mundial, protección e industrialización: ensayos de historia económica colombiana, Bogotá, CEREC, 1984a.

44. Ocampo, J. A. Colombia en la economía mundial, Bogotá, Siglo Veintiuno, Fedesarrollo, 1984b.

45. Ortiz, Z. H. “E1 Estado soberano del Cauca, 1858-1885”, tesis de Magíster en historia, Bogotá, Universidad Externado de Colombia, 1986. 
46. Páez M., C. P. "La administración fiscal de la renta del aguardiente en el Estado Soberano de Santander (1857-1886)”, monografía de pregrado, Bucaramanga, Universidad Industrial de Santander, 1998.

47. Rojas, Á. "Impactos monetarios e institucionales de la deuda pública en Colombia 1840-1890”, Borradores del CIE 2813, 2004.

48. Solano de las A., S. P., comp. Informe de los gobernadores de las provincias del Dpto. de Sucre, 1861-1882, Cartagena, Universidad de Cartagena, 2007.

49. Uthoff, L. M. "La difícil concurrencia fiscal y la contribución federal, 1861-1924. Notas Preliminares”, Historia Mexicana 61, 1, 2004.

50. Valencia L1., A. "La experiencia federal en el Estado Soberano del Cauca", Revista Historia y Espacio 30, 2008.

51. Van Ausdal, S. "Un mosaico cambiante: notas sobre una geografía histórica de la ganadería en Colombia, 1850-1950”, A. Flórez M., ed., El poder de la carne, Bogotá, Pontificia Universidad Javeriana, 2008. 